\title{
INTERPRETING AS A STRESSFUL ACTIVITY: PHYSIOLOGICAL MEASURES OF STRESS IN SIMULTANEOUS INTERPRETING
}

\author{
PAWEL KORPAL \\ Adam Mickiewicz University, Poznań \\ pkorpal@wa.amu.edu.pl
}

\begin{abstract}
The question of interpreter aptitude has been widely discussed in Interpreting Studies (e.g. Lambert 1991; Moser-Mercer 1994; Mackintosh 1999). Language command and cognitive skills have often been treated by interpreter trainers as the main determinants of an interpreter's future success. However, in recent years, more and more attention from interpreting scholars has been devoted to psycho-affective factors, such as motivation, anxiety or stress resistance (e.g. Timarová and Ungoed-Thomas 2008; Rosiers et al. 2011; Bontempo and Napier 2011). This paper presents the results of a pilot study, the main objective of which was to examine whether the speed of speaker's delivery influences the level of stress experienced by interpreting trainees during a simultaneous interpreting task. To this end, heart rate and blood pressure data were collected. The participants were asked to interpret two speeches from English into Polish. The author hypothesised that while interpreting a faster speech the participants would experience a higher level of stress than when they interpreted a slower speech. The hypothesis was corroborated only for heart rate values. No statistically significant differences were observed for either systolic or diastolic blood pressure. The study offers valuable insight into the question of stress experienced by interpreting trainees.
\end{abstract}

KEYWORDS: psychological stress; simultaneous interpreting; heart rate; blood pressure; interpreter aptitude.

\section{Introduction}

The last decades of the 20th century were marked by a cognitive turn in Translation and Interpreting Studies. As phrased by Rojo and Ibarretxe-Antuñano (2013: 8), at that point many translation scholars "deviated the attention from 
description of the translation product to research on the translation process". It appears that the same can be said about interpreting. Interpreting scholars expressed their interest in the processes inherent in both consecutive and simultaneous interpreting. Some theoretical models of simultaneous interpreting were developed (Gerver 1975; Moser-Mercer 1978; Darò and Fabbro 1994). Multitasking has often been discussed in the literature as a key feature of simultaneous interpreting (e.g. Gerver 1975, 1976; Gile 1995, 1999; Lambert 2004; Christoffels and de Groot 2005; Seeber 2011; Seeber and Kerzel 2011). Elsewhere, Gile (1995: 169) developed the idea of the Effort Models. He identified the main cognitive components of simultaneous interpreting, i.e. the Listening and Analysis Effort (L), the Short-term memory Effort (M), the Speech production Effort (P) and the Coordination Effort (C). The main idea behind Gile's models was that " $[\mathrm{i}]$ nterpreting requires some sort of 'mental energy' that is only available in limited supply" (Gile 1995: 161). Hence, each interpreter has a limited amount of cognitive resources at hand. It might happen that "[i]nterpreting takes up almost all of this mental energy, and sometimes requires more than is available, at which times performance deteriorates" (Gile 1995: 161).

In line with the cognitive turn in Interpreting Studies, the importance of memory skills in interpreters was widely researched (e.g. Daneman and Carpenter 1980; Padilla et al. 1995; Moser-Mercer et al. 2000; Chmiel 2012). One of the main questions posed in this context was whether professional interpreters are characterised by higher working memory capacity than interpreting trainees or non-interpreting bilinguals. The results of the studies are still inconclusive.

To summarise, the second part of the 20th century was characterised by the emergence of process-oriented research in Interpreting Studies. In line with the cognitive turn in interpreting research, linguistic and cognitive skills have often been treated by interpreting scholars as the main determinants of the interpreter's future success and crucial elements of their aptitude, understood as "a potential to attain ability" (Salkind 2008: 48). However, in recent years, the emergence of a new trend can be observed in Interpreting Studies. It appears that more attention has been devoted to the role of psycho-affective factors, such as motivation, anxiety or stress resistance in interpreting practice (e.g. Timarová and Ungoed-Thomas 2008; Rosiers et al. 2011; Bontempo and Napier 2011). This new trend will be referred to here as the psycho-affective turn in Interpreting Studies. 


\section{The psycho-affective turn}

There is more to interpreter aptitude than meets the eye. It goes without saying that linguistic and cognitive abilities are of great importance in an interpreter's job. However, several interpreting scholars have pointed out that the importance of psycho-affective and personality-related factors has been neglected in both theoretical considerations and interpreting practice:

- "most language learning approaches in general, and interpreter training programmes in particular, appear to disregard the learner as a human being and neglect the psycho-affective framework he brings to the task of learning a language" (Brisau et al. 1994: 87);

- "[a]s coping tactics are a fundamental skill in interpreting, they should be taught within the framework of practical exercises" (Kurz 2003: 64);

- "schools rarely administer tests explicitly aimed at more "soft" skills, such as motivation, ability to learn quickly, open-mindedness, etc., despite identifying these skills as an integral part of a good candidate" (Timarová and Ungoed-Thomas 2008: 43);

- "in subsequent decades, as conference interpreters came to do most of their work in the booth, the balance between cognitive and affective characteristics apparently shifted towards the former" (Pöchhacker 2011: 107);

- "[t]o concentrate research efforts on the cognitive factors that may predict performance in a profession is neglectful of the range of affective factors that have implications for the psychology of work" (Bontempo and Napier 2011: 87).

The psycho-affective turn in Interpreting Studies started to emerge as early as the 1990s (Brisau et al. 1994) but, as the claims cited above seem to suggest, it has become dominant in recent years. Some interpreting scholars have noticed that the psycho-affective framework of conference interpreting seems to have been neglected. Several studies have been conducted in recent years to fill this empirical void. Schweda Nicholson (2005: 137) carried out a study in which she used the Myers-Briggs Type Indicator (MBTI) to test interpreters' personality and found out, inter alia, that interpreters often favour a logical approach. Bontempo and Napier (2011: 101) showed that "emotional stability is a predictor of work performance for interpreters". Timarová and Salaets (2011) examined the role of soft skills, such as motivation, learning styles, resistance to stress and cognitive flexibility in interpreter training. They concluded that interpreters were more resistant to stress and showed greater cognitive flexibility than the 
non-interpreting control group. Such research leads us closer to the answer to a vital question about the existence of an 'ideal' psychological profile of a conference interpreter.

Chabasse (2009) developed an aptitude model for simultaneous interpreting in which psycho-affective factors play an important role. She enumerated skills which constitute important elements of interpreter aptitude for simultaneous interpreting. The model is presented here as Figure 1.

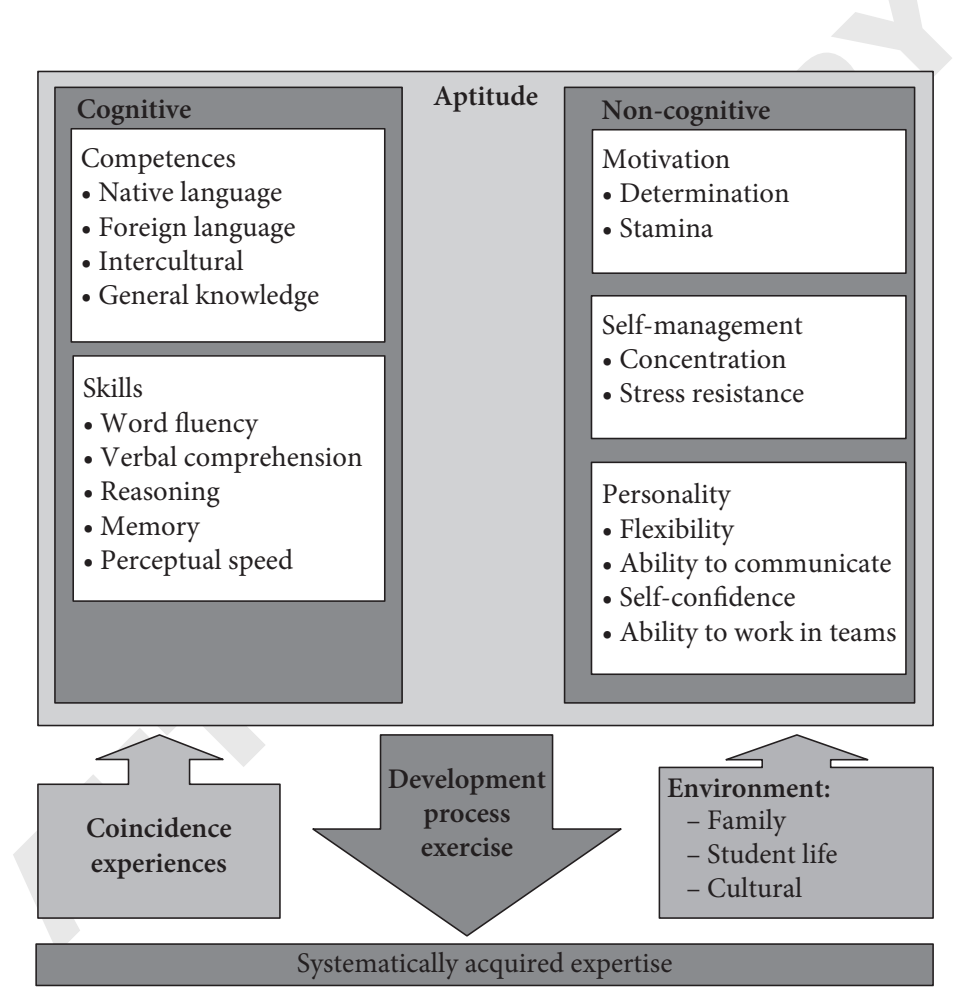

Figure 1. Aptitude model for simultaneous interpreting (Chabasse 2009, taken from Chabasse and Kader 2014: 21).

Chabasse (2009) makes a general distinction between cognitive and noncognitive components of interpreter aptitude. Within the former she emphasises the importance of a great command of both the interpreter's native and foreign language. General world knowledge and intercultural awareness are also includ- 
ed as cognitive components. Cognitive skills such as word fluency, verbal comprehension, reasoning, memory and perceptual span, traditionally recognised as vital elements of interpreter aptitude, constitute an important part of Chabasse's model. Crucial to this article is the inclusion of non-cognitive components in the aptitude model for simultaneous interpreting; Chabasse (2009) emphasises the importance of psycho-affective factors, such as motivation, self-management and personality, in interpreting.

\section{The definition of stress}

One of the non-cognitive components of interpreter aptitude mentioned by Chabasse (2009) is stress resistance. Interpreting scholars have often assumed, in an a priori fashion, that interpreting is a stressful activity. Nevertheless, as late as at the end of the 20th century empirical research on stress in interpreting was still surprisingly scarce. Cooper et al. (1982: 97) noted that "[a] great deal has been written about the pressures and strains imposed on interpreters working in international forums [...]. Little serious empirical work has been undertaken, however, to identify the sources of stress acting on them".

The notion of stress is a key issue in this article. The term has been widely discussed in fields such as medicine, psychology and pedagogy. Although stress seems to be inherent in the life of every individual, it is not that easy to define the term. It has been conceptualised differently over time and in different theoretical models. The two main theories of stress will be discussed here: the biological approach to stress developed by Selye $(1936 ; 1974 ; 1976)$ and the transactional model of stress developed by Lazarus and Folkman (1984).

Selye (1976) defined stress as "a state manifested by a specific syndrome which consists of all the nonspecifically induced changes within the biological system" (Selye 1976: 64). In his theory stress was conceptualised as a physiological reaction to a given stimulus. Selye (1974) introduced a distinction between distress and eustress. Distress is pathogenic and, if the organism is not able to cope with it, it may lead to the occurrence of a psychosomatic disorder. Eustress, on the other hand, is understood as a healthy stress which may function as a motivating factor helping a person to actively perform a given action.

Selye contributed greatly to stress research by modelling an organism's physiological response to a stimulus (stressor). What is more, he pointed out that stress does not always lead to disorder (distress vs. eustress). Nevertheless, Selye's theory has been criticised for one particular reason, i.e. the fact that it did not "take into consideration cognition, perception, and interpretation of the 
stimulus" (Rice 2011: 26). In other words, Selye's theory seems to turn a blind eye to individual differences in appraising a given objective situation as either stressful or non-threatening. By focusing so greatly on physiological aspects of stress, Selye neglected psychological processes which may impact stress and stress coping (Bishop 2001: 185).

Individual differences have been taken into consideration in the transactional model of stress developed by Lazarus and Folkman (1984). The authors define stress as "a particular relationship between the person and the environment that is appraised by the person as taxing or exceeding his or her resources and endangering his or her well-being" (Lazarus and Folkman 1984: 19, emphasis added). In this model, stress is not understood as a bodily reaction, but as a transaction between the objective characteristics of a situation/event and an individual's coping resources. For example, to claim that public speaking is distressing for every single person would be an overgeneralisation. In fact, what is perceived as a threat for one person may be only a (motivating) challenge for another. As phrased by Appley and Trumbull (1967: 7), "[w]ith the exception of extreme and sudden life-threatening situations, it is reasonable to say that no stimulus is a stressor to all individuals exposed to it". Furthermore, people use different coping abilities and resources when they face a stressful situation. In their theory, Lazarus and Folkman (1984) contributed to the psychology of stress by emphasising individual differences in coping with stress as well as in the cognitive appraisal of a given event.

\section{Physiological manifestation of stress in conference interpreting}

The aim of this section is to report on experimental studies in which physiological measures were used to investigate the notion of stress as experienced by conference interpreters and interpreting trainees. One of the landmark research projects on stress in conference interpreting was the Workload Study conducted by the Research Committee of the International Association of Conference Interpreters (AIIC). The research team investigated the following issues related to the interpreter's job: occupational stress, working environment and job satisfaction (Blumenthal et al. 2006). The researchers included a series of physiological measures of stress, i.e. ambulatory blood pressure (which is believed to identify people experiencing job strain and psychosocial stress), heart rate as well as salivary cortisol which is often referred to as the stress hormone (AIIC 2002: 48, after Kirschbaum and Hellhammer 1989). The research team demonstrated that interpreting is a highly stressful activity and that interpreters experience the 
highest level of stress when they are on mike, as opposed to being off mike and helping the active interpreter.

Apart from the Workload Study, a couple of other experiments on physiological manifestations of stress in conference interpreting have been conducted to date. For example, physiological stress responses were analysed in the study by Klonowicz (1994). The study used the following measures of stress: diastolic blood pressure, systolic blood pressure and heart rate. Klonowicz identified a "mobilization wave" when an increase in the values of all the measurements was observed. She emphasised "the functional significance of the pattern of changes in cardiovascular activity" (Klonowicz 1994: 221), i.e. that such a pattern helps interpreters prepare for and perform a challenging interpreting task.

Elsewhere, Moser-Mercer et al. (1998) investigated the effect of prolonged turns on interpreters' stress and the quality of interpretation. To this end, the researchers adopted a physiological measure of stress, i.e. cortisol concentration. The authors concluded that prolonged turns in simultaneous interpreting may indeed increase stress response values and hamper the quality of interpreting output (Moser-Mercer et al. 1998: 52). However, since only 5 interpreters participated in the study, one should be cautious about generalising the results onto the whole population of interpreters. Nevertheless, the experiment provided a valuable insight into the question of stress factors in simultaneous interpreting. Another study by Moser-Mercer (2005) examined whether remote interpreting would be more stressful than traditional (live) interpreting. A within-subject design was adopted, i.e. each participant interpreted under both remote and live conditions. In this experiment two physiological stress indicators were used: concentration of cortisol and immunoglobulin M (IgM) levels. The analysis of the results showed that remote interpreting was more stressful than live interpreting and led to a decline in performance faster than in the case of live interpreting (Moser-Mercer 2005: 92). This claim was also supported by the participants' self-reports.

Empirical work on the physiological manifestations of stress in interpreting have also been carried out by Kurz $(2002 ; 2003)$. In one of her studies she attempted to investigate whether media interpreting was more stress-provoking than on-site interpreting. Two physiological stress measures were adopted: skin conductance level (a type of electrodermal activity, also known as galvanic skin response) and pulse rate. Based on data collected during a 5-day conference the author demonstrated that media interpreting is indeed a more stressful activity than live interpreting (Kurz 2002: 200). In another study, Kurz (2003) compared the level of physiological stress during an interpreting task between novices and professionals by, again, measuring pulse rate and skin conductance level. Con- 
sistent with her hypothesis, Kurz (2003) obtained higher pulse rate values in novices. However, no statistically significant differences were observed in skin conductance level. As with Moser-Mercer et al. (1998), since Kurz examined only 2 professional interpreters and 3 novices, the conclusions formulated might seem tentative and should be treated with caution.

To summarise, some interpreting scholars have touched upon the question of physiological manifestation of stress in conference interpreting. The physiological markers of stress which were used in such research included: heart rate, blood pressure, skin conductance level, cortisol concentration and IgM levels. In a majority of the studies, a specific independent variable was abstracted (e.g. interpreting setting, prolonged turns in simultaneous interpreting) in order to verify whether it had an impact on stress as experienced by interpreters during an interpreting task.

The main focus of this section was on physiological measures of stress. However, it should be mentioned here that self-reported stress and anxiety have also been researched in Interpreting Studies by means of adopting psychometric instruments such as the Foreign Language Classroom Anxiety Scale (FLCAS) developed by Horwitz et al. (1986) or the State-Trait Anxiety Inventory by Spielberger et al. (1970). In survey research participants are asked to fill in a questionnaire in which they are asked about their current mental or emotional state. For details on the results of studies on self-reported stress/anxiety in interpreting, see: Cooper et al. (1982), Jiménez Ivars and Pinazo Calatayud (2001), Chiang (2009), Chiang (2010) and Kao and Craigie (2013).

\section{A pilot study}

In the empirical part of this article the results of the pilot study will be presented in which pulse rate and blood pressure were used to examine physiological stress responses in simultaneous interpreting. The study is part of a larger project in which physiological measures of stress are supplemented with psychometric tests as well as acoustic markers of stress. However, self-reported stress and linguistic indicators of stress are beyond the scope of this article.

\subsection{The aim of the study}

As already suggested, although a great many interpreters would agree that interpreting is a stress-provoking activity, only a few studies on psychological stress 
in interpreting have been conducted so far. There seems to be a need to validate this point by means of empirical work which would indicate which factors may influence the interpreter's job negatively. Such factors were referred to by Gile (1995: 188) as "problem triggers" which included inter alia: strong foreign accent, proper names, enumerations and a high rate of delivery. They usually require extra processing capacity on the part of the interpreter which might in turn compromise interpreting quality. Rate of delivery has often been regarded as problematic in simultaneous interpreting (e.g. Gerver 1969; Barik 1973; Gile 1995). Although interpreting fast speakers has been considered to be cognitively challenging, its effect on psychological stress experienced by interpreters has not been researched yet in an experimental setting.

Thus, the main objective of the study was to investigate whether the speaker's rate of delivery (independent variable) would influence the level of stress (dependent variable) experienced by interpreting trainees in a simultaneous interpreting task. To this end, heart rate and blood pressure were used as physiological markers of stress. An experimental setting made it possible to attempt to establish a causal relationship between the speed of delivery and psychological stress operationalised by heart rate and blood pressure.

\subsection{Participants}

Ten interpreting trainees took part in the pilot study. They were students of the interpreting programme at the Faculty of Modern Languages and Literatures of Adam Mickiewicz University. The experiment was carried out in May and June 2014, shortly before the students' final interpreting exam. In other words, completion of at least 3 semesters of the interpreting programme served as one of the inclusion criteria in this study. There were 7 female and 3 male students in the experimental group, the mean age was 24.8 ranging from 23 to 26 years. All participants were native speakers of Polish. Five of them had English as a B language, the remaining ones (also five students) had English as a $\mathrm{C}$ language.

\subsection{Materials and procedure}

At the beginning of the experiment the students were familiarised with the whole procedure. They were asked to simultaneously interpret two speeches from English into Polish and were then asked to participate in a semi-structured interview (see below). The speeches were designed in such a way that they were 
differentiated only by the level of the independent variable (high vs. low speed of delivery). Each participant interpreted one speech under the slow-speed condition and one speech under the fast-speed condition. In order to reduce the impact of any confounding variables, the speeches were similar in terms of their topic and structure. Both speeches were prepared in two delivery rates by means of the Audacity software. The order of texts presented was counterbalanced among the participants so as to avoid the impact of fatigue on the results of the experiment. The length of the recordings in both conditions is presented below in Table 1.

Table 1. The length (in sec) and speed (in words/min) of each recording.

\begin{tabular}{lcc}
\hline & Slow & Fast \\
\hline Speech 1 (Copenhagen) & $10 \mathrm{~min} 43 \mathrm{sec}$ & $8 \mathrm{~min} 43 \mathrm{sec}$ \\
& $(107 \mathrm{words} / \mathrm{min})$ & $(144 \mathrm{words} / \mathrm{min})$ \\
Speech 2 (Stockholm) & $10 \mathrm{~min} 40 \mathrm{sec}$ & $8 \mathrm{~min} \mathrm{32} \mathrm{sec}$ \\
& $(106 \mathrm{words} / \mathrm{min})$ & $(143 \mathrm{words} / \mathrm{min})$ \\
\hline
\end{tabular}

All the interpretations were recorded for further analysis. Each participant was assigned a code so to ensure anonymity when analysing the results of the experiment.

Both heart rate and blood pressure were measured four times during the course of the experiment. To this end, a "POLAR" heart-rate monitor and a "Novama" pressure gauge were used. The following heart rate values were collected: (1) a single value at the beginning of the experiment, (2) the mean heart rate value for the first minute of the slow speech, (3) the mean heart rate value for the first minute of the fast speech and (4) a single value after the interview which followed the main experiment (baseline value). Analysing heart rate values only during the first minute of each interpretation was a conscious decision by the author of the study. One of the characteristics of distress is that when it occurs the organism mobilises the available resources to cope with it as soon as possible. Hence, it seemed reasonable to focus on the heart rate values during the first minute of the speech when the organism had not yet had a chance to cope with the potentially stressful experience. As for the blood pressure, the following four values were collected: (1) at the beginning of the experiment, (2) after the interpretation of the slow speech (3) after the interpretation of the fast speech and (4) after the interview following the experiment (baseline value). 
The aim of the semi-structured interview administered after the experiment was to collect self-reported data on the following topics:

(1) potential stressors in interpreting;

(2) the difference between consecutive and simultaneous interpreting with regard to the level of stress experienced by the participants;

(3) stress coping strategies used by the participants.

Each recording session ended with a debriefing, during which the participants were familiarised with the main objective of the project.

\subsection{The main hypothesis}

The null hypothesis preceding the experiment was that there would be no difference in stress levels between the slow-speech condition and the fast-speech condition as reflected in heart rate and blood pressure values.

The experiment was designed as an attempt to refute the null hypothesis. The main hypothesis can be thus formulated as follows: the speaker's speed of delivery has an influence on the stress level experienced by the interpreting trainees in a simultaneous interpreting task. To be more specific, while interpreting the faster speech the participants would experience a higher level of stress (manifested by higher heart rate and higher blood pressure) than when they interpreted a slower speech.

\subsection{Results}

A within-subject design was adopted in this study to investigate changes in stress levels as a result of experimental manipulation.

A repeated measures ANOVA was conducted in order to study changes in the pulse rate throughout the task (before the experiment, the mean pulse rate value during the first minute of the slow speech, the mean pulse rate value during the first minute of the fast speech, after the experiment). The results show that the pulse rate changes in the course of the experiment are statistically significant, $F(3,27)=10.197, p=.001, \eta_{\mathrm{p}}{ }^{2}=.531$. Pairwise comparisons show that the difference between the slow-speed condition and the fast-speed condition is statistically significant $(p=.023)$. 
Table 2. Heart rate: Means for all conditions (with standard deviations $=S D$ ).

\begin{tabular}{lcccc}
\hline & Before & $\begin{array}{c}\text { Slow } \\
\text { (1st minute) }\end{array}$ & $\begin{array}{c}\text { Fast } \\
\text { (1st minute) }\end{array}$ & $\begin{array}{c}\text { After } \\
\text { (baseline) }\end{array}$ \\
\hline Mean heart rate & $M=91.00$ & $M=94.80$ & $M=102.60$ & $M=86.10$ \\
& $S D=10.98$ & $S D=10.84$ & $S D=14.49$ & $S D=8.02$ \\
\hline
\end{tabular}

Table 3. Systolic (maximum) blood pressure:

Means for all conditions (with standard deviations $=S D$ ).

\begin{tabular}{lcccc}
\hline & Before & Slow & Fast & After (baseline) \\
\hline Mean systolic & $M=128.70$ & $M=132.30$ & $M=128.90$ & $M=124.90$ \\
blood pressure & $S D=11.71$ & $S D=17.92$ & $S D=17.23$ & $S D=13.96$ \\
\hline
\end{tabular}

Table 4. Diastolic (minimum) blood pressure:

Means for all conditions (with standard deviations $=S D$ ).

\begin{tabular}{lcccc}
\hline & Before & Slow & Fast & After (baseline) \\
\hline Mean diastolic & $M=91.40$ & $M=93.50$ & $M=91.00$ & $M=90.00$ \\
blood pressure & $S D=12.52$ & $S D=16.19$ & $S D=14.17$ & $S D=14.20$ \\
\hline
\end{tabular}

Repeated measures ANOVA tests were also conducted to study changes in both systolic and diastolic blood pressure throughout the task (before the experiment, after the interpretation of the slow speech, after the interpretation of the fast speech, after the experiment). No statistically significant results were obtained for systolic blood pressure, $F(3,27)=.850, p=.449$. Similarly, the analysis of diastolic blood pressure values did not show any statistically significant results, $F(3,27)=.394, p=.758$. Thus, the main hypothesis was corroborated only for the heart rate values.

As already mentioned, the experiment was followed by a semi-structured interview with each participant. Each session lasted around 10 minutes during which data on potential stressors in interpreting and stress coping strategies were collected. The interviews were recorded for later analysis. With regards to the stressors, the majority of participants mentioned public speaking as the main challenge in consecutive interpreting. A great many trainees reported that the mere fact that they needed to perform in front of other people increased their 
level of stress and made them more anxious about the task. When asked about the difference between consecutive and simultaneous interpreting with regard to the level of stress experienced by the participants, the majority of them declared that the former is much more stressful. During simultaneous interpreting, they felt more isolated from the communicative situation; not being in the spotlight made them feel more secure.

Another factor which was frequently mentioned by the participants was the fear of making mistakes, especially in consecutive interpreting during which accuracy errors may be identified by the part of the audience which has a sufficient command of both the source and target language. This kind of perfectionism appears to be a burden for many students of conference interpreting, who get frustrated when they fail to provide an error-free interpretation. Such an observation was confirmed by the participants' numerous comments made during the interview.

Other stressors discussed by the participants fell into the category of unsatisfactory working conditions. In simultaneous interpreting the trainees mentioned poor sound and visibility as well as no access to the visual materials presented by the speaker. More interestingly for this discussion, four out of ten participants referred to rate of delivery as a significant stress factor in conference interpreting.

During the interview the participants were also asked about how they dealt with stress in interpreting. Since only self-reported data were collected in the interview, such a discussion must be limited to only those behaviours and strategies which are consciously used by the students who took part in the study. The most frequently mentioned ideas are listed and discussed below:

- Positive reinterpretation (Carver et al. 1989): when being confronted with a stressful situation, it might be useful to try to perceive it in a more favourable light. Some interviewees declared that they applied such a way of thinking before exams. They tried to focus on the bright side of the whole situation and convince themselves that they were skilled enough to pass the exam. Such emotion-oriented coping (Lazarus and Folkman 1984) was considered to be effective by the participants who mentioned it during the interview.

- Belief in one's skills: one of the respondents stated that he had built up confidence about his interpreting skills for a couple of months. At first he was very unsure about the quality of his interpretations but the positive feedback provided by his teachers made him believe in his abilities. As reported by 
the respondent, this kind of self-esteem helped him feel less anxious in the interpreting classroom.

- Isolation and focus on the task: some trainees reported that in order to deal with the stress inherent in interpreting practice, they focus on the task itself. The idea behind task-oriented coping (Lazarus and Folkman 1984) in simultaneous interpreting is that interpreters isolate themselves from the interpreting context in order to reduce anxiety. A study conducted by the author of this article has proved that task-oriented coping is a predominant stress coping strategy used by professional interpreters and interpreting trainees with no statistically significant differences between both groups (Korpal 2015).

- Preparation: the majority of interviewees claimed that being prepared for the class helps to reduce stress in the interpreting classroom. To give an example, background research on the topic assigned by the teacher made the participants more confident that they were able to provide a high-quality interpretation. Preparation enhanced the students' self-efficacy, understood as one's belief in the ability to succeed in a given task (Bandura 1977).

- Sufficient rest: one of the students stated that the experience of stress and anxiety seemed to be correlated with her physical and cognitive well-being. In other words, being well-rested may translate into a more positive attitude towards a given interpreting task and, as a result, may boost interpreting quality. On the other hand, there is a great chance that fatigue and overwork will be reflected in a student's anxiety and unsatisfactory interpreting quality.

- Supporting interpreter: it was also frequently mentioned that simultaneous interpreting is less stressful when a student was accompanied by another student in the booth. The respondents reported that they had practiced teamwork during the class and felt that the presence of another interpreter helped to reduce stress.

\subsection{Discussion and conclusions}

The main objective of the pilot study was to investigate whether there exists a causal relationship between the speaker's rate of delivery and the level of stress experienced by the interpreting trainees. Two physiological measures were used to operationalise stress: heart rate and blood pressure. The hypothesis was cor- 
roborated only with respect to heart rate as a physiological indicator of stress. The analysis of blood pressure values, on the other hand, did not allow the author to refute the null hypothesis and obtain data about the impact of the speed of delivery on interpreters' stress.

The pilot study did not reveal any errors in the experimental procedure. The only change which should, and will, be introduced in subsequent research is that blood pressure data will no longer be collected. As has been manifested in the pilot study, blood pressure did not prove to be a valid measure of stress in the experimental setting involving a simultaneous interpreting task. It seems that high blood pressure (hypertension) has been recognised as a marker of chronic stress in a person's life. In other words, hypertension may correlate with life stress. However, momentary stress induced in the experimental setting appears not to be reflected in the person's blood pressure. Such a realisation implies that blood pressure will not prove useful in this project as a stress marker, and thus will not be applied when recording further participants.

The analysis of heart rate values as well as the interviews with the participants revealed that simultaneous interpreting may indeed be considered a stressful activity. The results obtained are on a par with the results of the Workload Study conducted by the AIIC team (2002). As suggested by Pöchhacker (2011: 107), in recent decades there has been a tendency to focus on the cognitive characteristics of the interpreting process while neglecting the psychological aspects of the interpreting practice. This study serves as an empirical verification of the common belief, discussed by e.g. Gerver (1969), Barik (1973) and Gile (1995) that high rate of delivery may indeed be a problem trigger in simultaneous interpreting. In the pilot study the author focused only on the physiological manifestation of stress experienced by interpreting trainees in simultaneous interpreting. In the experiment proper, the State-Trait Anxiety Inventory (STAI) will be administered as well. STAI measures two types of anxiety - state anxiety (STAI X-1, anxiety about an event) and trait anxiety (STAI X-2, being anxious as a stable characteristic of a given person) (Spielberger et al. 1970). STAI X-1 is a useful psychometric tool which makes it possible to investigate changes in the anxiety level as a result of experimental manipulation. What is more, two experimental groups will take part in the main study: interpreting trainees and professional interpreters. It is assumed that professional interpreters will experience a lower level of stress, when compared with interpreting trainees, as practice will make professionals more used to stressful working conditions. Comparing data obtained for both experimental groups will make it possible to check the veracity of this claim. 
Conducting a pilot study made the author aware of some ethical considerations related to studies involving experimental manipulation of human behaviour. The use of a heart-rate monitor and the analysis of the physiological reactions of a human body might have led to the participants' discomfort and, in turn, increased the level of anxiety. Thus, it is of great importance to include information on the use of apparatus in a written consent form and explain to the participants how the heart-rate monitor works. Moreover, one of the biggest challenges of studies on psychological stress is that it is difficult to isolate stress resulting from the effect of an independent variable from stress experienced as a result of participation in the experiment. It is possible, and indeed likely, that the participants may be exposed to test anxiety and fear of negative evaluation ( $\mathrm{Du}$ 2009: 163). Test anxiety should be understood as a psychological state in which a student is distressed as they are aware of the fact that their performance will be assessed by experts. Fear of negative evaluation, on the other hand, is related to fear of being criticised by others (Du 2009: 163). Hence, it is crucial to ensure the participants' anonymity. Fear of negative evaluation can be even more problematic when there is a teacher-student relationship between the experimenter and the participants. Thus, assessment apprehension is a crucial issue and should not be neglected when conducting experiments.

It should also be remembered that an experimental setting may compromise the ecological validity of studies on conference interpreters. What the results of the pilot study seem to suggest is that interpreting fast speakers is a considerable stressor when performing an experimental task. One should be cautious about generalising these results onto interpreters' natural working environments.

Quite a small number of participants might, on the other hand, impact the external validity of the study. This problem has been often discussed by interpreting scholars (e.g. Gile 1995, O'Brien 2010). Notwithstanding the potential weaknesses of the research described here, it appears that the study offers valuable insight into the question of stress experienced by interpreting trainees.

\subsection{Didactic considerations}

From the didactic perspective, the project is important as it suggests that interpreter trainers should not neglect the psychological aspects of interpreting practice. Research on the cognitive aspects of conference interpreting has been dominant for the last couple of decades. There is a general consensus among interpreter trainers that language and cognitive skills play a pivotal role in the interpreting classroom. For instance, memory enhancement exercises are often of- 
fered in interpreter training. What appears to be neglected are the psychologyand personality-related difficulties inherent in interpreting practice. It should be remembered that exposure to stress may make it more difficult for a student to perform an interpreting task which, in turn, may be reflected in the low quality of interpreting output. Similarly, anxiety experienced by a given student may make it more difficult to show their interpreting skills. As such, it would be a good idea to include stress coping strategies in interpreter training (Horváth 2012: 169). Interpreter trainers should accept that stress is an inherent part of conference interpreting. Their task is to identify stressful situations in the classroom so as to be able to help students find appropriate solutions which, in turn, may boost the quality of the novices' interpretations.

\section{Acknowledgements}

The study is part of the author's $\mathrm{PhD}$ project entitled "Linguistic and psychological indicators of stress in simultaneous interpreting". The author is grateful to Prof. Bogusława Whyatt and Dr. Agnieszka Chmiel who have supervised the work on the project and contributed greatly to its final shape. Also, the author would like to thank Katarzyna Stachowiak for her valuable help in collecting data and carrying out the experiment.

\section{REFERENCES}

AIIC (International Association of Conference Interpreters). 2002. Workload study-full report. Available at:

$<$ http://aiic.net/page/657/interpreter-workload-study-full-report/lang/1>. (Last accessed 17 Feb 2015.)

Appley, H. and R. Trumbull. 1967. "On the concept of psychological stress”. In: Appley, H. and R. Trumbull (eds.), Psychological stress: Issues in research. New York: Meredith Publishing Company. 1-13.

Bandura, A. 1977. "Self-efficacy: Toward a unifying theory of behavioral change". Psychological Review 84(2). 191-215.

Barik, H. 1973. "Simultaneous interpretation: Temporal and quantitative data". Language and Speech 16. 237-270.

Bishop, G. 2001. Psychologia zdrowia [Health psychology]. Wrocław: Wydawnictwo Astrum.

Blumenthal, P., T. Britt, J. Cohen, J. McCubbin, N. Maxfield, E. Michael, P. Moore, L. Obler, P. Scheck, T. Signorelli and T. Wallsten. 2006. "Stress effects on language professionals' performance”. International Journal of Bilingualism 10(4). 477-495. 
Bontempo, K. and J. Napier. 2011. "Evaluating emotional stability as a predictor of interpreter competence and aptitude for interpreting". Interpreting 13. 85-105.

Brisau, A., R. Godijns and C. Meuleman. 1994. "Towards a psycholinguistic profile of the interpreter". Meta: Translators' Journal 39(1). 87-94.

Carver, C., M. Scheier and J. Weintraub. 1989. "Assessing coping strategies: A theoretically based approach". Journal of Personality and Social Psychology 56(2). 267283.

Chabasse, C. 2009. Gibt es eine Begabung für das Simultandolmetschen?: Erstellung eines Dolmetscheignungstests mit Schwerpunkt Simultandolmetschen. Berlin: SAXA Verlag.

Chabasse, C. and S. Kader. 2014. "Putting interpreting admissions exams to the test: The MA KD Germersheim Project". Interpreting 16(1). 19-33.

Chiang, Y.-N. 2009. "Foreign language anxiety in Taiwanese student interpreters". Meta: Translators' Journal 54(3). 605-621.

Chiang, Y.-N. 2010. "Foreign language anxiety and student interpreters' learning outcomes: Implications for the theory and measurement of interpretation learning anxiety". Meta: Translators' Journal 55(3). 589-601.

Chmiel, A. 2012. "Pamięć operacyjna tłumaczy konferencyjnych mierzona metodą RSPAN" [Interpreters' working memory measured by the RSPAN method]. In: Piotrowska, M. (ed.), Kompetencje tłumacza. Kraków, Tertium. 137-154.

Christoffels, I. and A. de Groot. 2005. "Simultaneous interpreting: A cognitive perspective”. In: Kroll, J. and A. de Groot (eds.), Handbook of bilingualism: Psycholinguistic approaches. New York: Oxford University Press. 454-479.

Cooper C., R. Davies and R. Tung. 1982. "Interpreting stress: Sources of job stress among conference interpreters". Multilingua 1(2). 97-107.

Daneman, M. and P. Carpenter. 1980. "Individual differences in working memory and reading". Journal of Verbal Learning and Verbal Behavior 19. 450-466.

Darò, V. and F. Fabbro. 1994. "Verbal memory during simultaneous interpretation: Effects of phonological interference". Applied Linguistics 15(4). 365-381.

$\mathrm{Du}, \mathrm{X} .2009$. "The Affective Filter in second language teaching". Asian Social Science 5(8). 162-165.

Gerver, D. 1969. "The effects of source language presentation rate on the performance of simultaneous conference interpreters". In: Foulke, E. (ed.), Proceedings of the 2nd Louisville Conference on Rate and/or Frequency Controlled Speech. University of Louisville. 162-184.

Gerver, D. 1975. "A psychological approach to simultaneous interpretation”. Meta: Translators' Journal 20(2). 119-128.

Gerver, D. 1976. "Empirical studies of simultaneous interpreting: A review and a model”. In: Brislin, R. (ed.), Translation. New York: Gardner Press. 165-207.

Gile, D. 1995. Basic concepts and models for interpreter and translator training. Philadelphia: John Benjamins.

Gile, D. 1999. "Testing the Effort Models' tightrope hypothesis in simultaneous interpreting - a contribution". Hermes 23. 153-172.

Horváth, I. 2012. Interpreter behaviour: A psychological approach. Budapest: Hang Nyelviskola Bt. 
Horwitz, E., M. Horwitz and J. Cope. 1986. "Foreign language classroom anxiety". In: Horwitz, E. and D. Young (eds.), Language anxiety: From theory and research to classroom implications. Englewood Cliffs, NJ: Prentice Hall. 27-36.

Jiménez Ivars, A. and D. Pinazo Calatayud. 2001. "I failed because I got very nervous. Anxiety and performance in interpreting trainees: An empirical study". The Interpreters' Newsletter 9. 21-39.

Kao, P.-C. and P. Craigie. 2013. "Evaluating student interpreters' stress and coping strategies". Social Behavior and Personality 41(6). 1035-1044.

Kirschbaum, C. and D. Hellhammer. 1989. "Salivary cortisol in physiological research: An overview". Neuropsychology 22. 150-169.

Klonowicz, T. 1994. "Putting one's heart into simultaneous interpretation”. In: Lambert, S. and B. Moser-Mercer (eds.), Bridging the gap: Empirical research in simultaneous interpretation. Amsterdam: John Benjamins. 213-224.

Korpal, P. 2015. "I will do it! Stress coping strategies used by interpreting trainees and professional conference interpreters". Paper presented at the 11th International Postgraduate Conference in Translation and Interpreting, Edinburgh, 28-30 Nov 2015.

Kurz, I. 2002. "Physiological stress responses during media and conference interpreting". In: Garzone, G. and M. Viezzi (eds.), Interpreting in the 21st century. Amsterdam: John Benjamins. 195-202.

Kurz, I. 2003. "Physiological stress during simultaneous interpreting: A comparison of experts and novices". The Interpreters' Newsletter 12. 51-67.

Lambert, S. 1991. "Aptitude testing for simultaneous interpretation at the University of Ottawa”. Meta: Translators' Journal 36(4). 586-594.

Lambert, S. 2004. "Shared attention during sight translation, sight interpretation and simultaneous interpretation”. Meta: Translators' Journal 49(2). 294-306.

Lazarus, R. and S. Folkman. 1984. Stress, appraisal, and coping. New York: Springer Publishing Company.

Mackintosh, J. 1999. "Interpreters are made not born". Interpreting 4(1). 67-80.

Moser-Mercer, B. 1994. "Aptitude testing for conference interpreting: Why, when and how". In: Lambert, S. and B. Moser-Mercer (eds.), Bridging the gap: Empirical research in simultaneous interpretation. Amsterdam: John Benjamins. 57-68.

Moser-Mercer, B. 1978. "Simultaneous interpretation: A hypothetical model and its practical application". In: Gerver, D. and H. Sinaiko (eds.), Language communication and interpretation. New York: Plenum Press. 353-368.

Moser-Mercer, B. 2005. "Remote interpreting: The crucial role of presence". Bulletin VALS-ASLA (Swiss association of applied linguistics) 81. 73-97.

Moser-Mercer, B., A. Künzli and M. Korac. 1998. "Prolonged turns in interpreting: Effects on quality, physiological and psychological stress (pilot study)". Interpreting 3(1). 47-64.

Moser-Mercer, B., U. Frauenfelder, B. Casado and A. Künzli. 2000. "Searching to define expertise in interpreting". In: Dimitrova, B. and K. Hyltenstam (eds.), Language processing and simultaneous interpretation: Interdisciplinary perspectives. Amsterdam: John Benjamins. 107-131.

O’Brien, S. 2010. "Eye tracking in translation process research: Methodological challenges and solutions". Copenhagen Studies in Language 38. 251-266. 
Padilla, P., M. Bajo, J. Cañas, and F. Padilla. 1995. "Cognitive processes of memory in simultaneous interpretation”. In: Tommola, J. (ed.), Topics in interpreting research. Turku: University of Turku Press. 61-71.

Pöchhacker, F. 2011. "Assessing aptitude for interpreting: The SynCloze test". Interpreting 13(1). 106-120.

Rice, V. 2011. "Theories of stress and its relationship to health". In: Rice, V. (ed.), Handbook of stress, coping, and health: Implications for nursing research, theory, and practice. Los Angeles: Sage Publications. 22-42.

Rojo, A. and I. Ibarretxe-Antuñano. 2013. "Cognitive linguistics and Translation Studies: Past, present and future”. In: Rojo, A. and I. Ibarretxe-Antuñano (eds.), Cognitive linguistics and translation: Advances in some theoretical models and applications. Berlin: Mouton de Gruyter. 3-30.

Rosiers, A., J. Eyckmans and D. Bauwens. 2011. "A story of attitudes and aptitudes? Investigating individual difference variables within the context of interpreting". Interpreting 13(1). 53-69.

Salkind, N.J. (ed.). 2008. Encyclopedia of educational psychology. Los Angeles: SAGE Publications.

Schweda Nicholson, N. 2005. "Personality characteristics of interpreter trainees: The Myers-Briggs Type Indicator (MBTI)”. The Interpreters' Newsletter 13. 110-142.

Seeber, K. 2011. "Cognitive load in simultaneous interpreting: Existing theories - new models". Interpreting 13(2). 176-204.

Seeber, K. and D. Kerzel. 2011. "Cognitive load in simultaneous interpreting: Model meets data". International Journal of Bilingualism 16(2). 228-242.

Selye, H. 1936. "A syndrome produced by diverse nocuous agents". Nature 138. 32.

Selye, H. 1974. Stress without distress. Philadelphia: J. B. Lippincott Company.

Selye, H. 1976. The stress of life. (Revised ed.) New York: McGraw-Hill Book Company.

Spielberger, C., R. Gorsuch and R. Lushene. 1970. The State-Trait Anxiety Inventory: Test manual. Palo Alto: Consulting Psychologist Press.

Timarová, Š. and H. Ungoed-Thomas. 2008. "Admission testing for interpreting courses". The Interpreter and Translator Trainer 2(1). 29-46.

Timarová, Š. and H. Salaets. 2011. "Learning styles, motivation and cognitive flexibility in interpreter training: Self-selection and aptitude". Interpreting 13(1). 31-52.

\author{
Address correspondence to: \\ Paweł Korpal \\ Faculty of English \\ Adam Mickiewicz University \\ Collegium Novum \\ al. Niepodległości 4 \\ 61-874 Poznań \\ Poland \\ pkorpal@wa.amu.edu.pl
}

